\title{
Near-Death Experiences in a Southern California Population
}

\author{
J. Timothy Green \\ Penelope Friedman \\ California State University, Northridge
}

\begin{abstract}
In-depth interviews with 41 persons who were near death or clinically dead as the result of an accident, illness, or suicide attempt are presented. Respondents reported a total of 50 near-death experiences (NDEs) of which 33 were rated (using K. Ring's Weighted Core Experience Index) as having been deep, 10 as moderate, and 7 as non-experiences. Results are presented in terms of the characteristics of each of the five stages of the NDE. Results are interpreted as being consistent with the hypothesis that the experiencers entered into an altered dimension of reality or existence.
\end{abstract}

\section{INTRODUCTION}

Although published systematic accounts of events surrounding near-death episodes date as far back as the late eighteen hundreds (Heim, 1892), it was not until the publication of the best-selling book, Life After Life (Moody, 1975), that this field of investigation began to receive widespread interest, not only from the lay public but also from a number of established researchers and scientists. Moody, who coined the term near-death experience (NDE), outlined a series of events reported to him by persons who were near death or clinically dead and then resuscitated. These events included a sensation of being outside one's physical body; feeling intense peace, calm, and painlessness; floating down a dark, tunnel-like area; seeing a brilliant light, which often contained a presence Moody called a "being of light"; viewing the spirits of dead relatives and friends; and seeing an instantaneous replay of one's life.

Kenneth Ring's book, Life At Death (1980), presented a more scientific treatment of this subject. Ring's work supported Moody's in all major areas and also provided some important parameters. For instance, Ring found that 48 percent of his sample of 102 people reported having had an experience similar to that outlined by Moody. Ring also found that the manner in which a person came near death did not significantly affect whether he reported an experience or the depth of the reported experience. The most important part of 
Ring's study was identification of the five core components of the NDE. These are (1) the core affective cluster, (2) the out-of-body experience, (3) the tunnel or dark area, (4) seeing the light, and (5) entering the light. Ring found these five components were often reported in that sequence and that a greater percentage of the first was reported than the second, more of the second than the third, and so forth.

Michael Sabom, in his recent book, Recollections of Death (1982), outlined the general features of the NDE and distinguished between two types: the autoscopic and the transcendental. In his sample of 116 persons, Sabom found the general features associated with both types of NDE include a sense of ineffability, a sense of timelessness, a sense of reality, an intuitive feeling of death, feelings of peace, calm, and painlessness, and the perception of having left one's body. Autoscopic experiences (called out-of-body experiences by others), which were reported by 32 persons in Sabom's study, entail a sensation of leaving one's body and being able to see and, less frequently, to hear what happens in the vicinity. Sabom presented some interesting corroborative evidence by first interviewing experiencers and then reviewing medical charts and interviewing staff. Transcendental experiences, which were reported by 41 persons in Sabom's study, include the tunnel or darkness, the light, the transcendental environment, encounters with others, the life review, and the return.

In another study, one that most closely resembles our own, James H. Lindley, Sethyn Bryan, and Bob Conley (1981) interviewed 49 persons in the Pacific Northwest who described a total of 55 NDEs. The focus of their study was on the stages of the experience. Their results were similar to Ring's, although they reported somewhat higher percentages of their sample experiencing each of the core components. These researchers were particularly impressed with the aftereffects of the NDE on experiencers, some of whom reported major changes in their values, ideals, and relationships. Finally, these researchers and others have reported that experiencers express significantly less fear of death following NDEs.

Our study is an attempt to replicate the results outlined above, drawing from a population in the Greater Los Angeles area.

\section{METHOD}

Beginning in January, 1981, we placed the following advertisement in several newspapers in the Los Angeles area: 
Psychological researcher interested in interviewing persons who have been close to death or clinically dead.

We were also able to recruit respondents through referrals. Of our sample, 29.3 percent were referred to us; the remainder responded to the advertising. Our criteria for inclusion in the study were these: (1) the person had to be eighteen years of age or older at the time of the interview, (2) the person had to have been near death or clinically dead as the result of accident, illness or suicide attempt, and (3) the person had to have recovered sufficiently to be interviewed. We screened calls before going out on interviews by first establishing that the caller had been near death, then asking the following question:

A number of researchers have found that some people who come very close to death report having had an experience while unconscious. Did anything unusual happen to you?

If the potential respondent then went on to describe any of the components commonly associated with the NDE and agreed to be interviewed in person, we scheduled an interview. There were many callers who either refused to be interviewed or did not meet requirements for inclusion in our study.

All interviews were conducted in person, tape recorded in full, and later transcribed as needed. We assured all respondents of confidentiality and anonymity. Interviews ranged from approximately one half-hour to more than two hours. We used a structured interview schedule (Ring, 1980) that consisted of (1) gathering demographic information, (2) recording the respondent's narrative of the events leading up to the experience and the experience itself, and (3) probing the salient features of the experience. We used the Weighted Core Experience Index (Ring, 1980) in order to quantify the data. The two authors independently rated each experience, and only if both of us agreed that a given component was present was it scored as having occurred.

\section{RESULTS}

We interviewed 41 respondents, 15 men and 26 women, reporting a total of 50 NDEs. In our study 1 man and 2 women reported 3 experiences. The ages of our respondents ranged from 18 to 67 with a mean age of 40 at the time of the interview, while the mean age at the time of NDE was 29. Although more than 10 years had passed 
between the time of the experience and this study for many of the participants, their accounts were amazingly vivid. One woman's NDE occurred at age 3 , but she still was able to give a detailed narrative at age 21 . In our study 24 respondents came near death as the result of an illness, 22 were in accidents, and 4, all female, had attempted suicide. Based on the Weighted Core Experience Index ratings, 43 experiences ( 86 percent of the sample) contained enough components to qualify as either a deep or moderate near-death experience. We rated 7 (14 percent) as not containing enough components to qualify as NDEs.

\section{Stage One: Core Affective Cluster}

Of the persons who agreed to speak with us, 35 (70 percent) related feelings of overwhelming peace, calm, and painlessness. Many reported their feelings to be unlike anything that they had ever experienced before. A number of respondents expressed these feelings in very emotional terms although they stated there was no way to convey what they had experienced.

A woman who had a near fatal heart attack said:

... I'm not in pain anymore ... as though $I$ have shed something ... all of my problems. Boy did I feel good. I just felt marvelous. I don't think that there are words in the whole world to tell you. It was beautiful.

A man whose experience occurred while undergoing quadruple bypass surgery had this to say:

It was that state of being that we would all like to be in, where everything is perfect, where you have no anxieties, no pressure, no fear whatsoever. Perfection is the only way I can put it.

We heard similar statements over and over again describing what for many was the first component of their NDE. This core affective cluster was not described as a stage that ended but as part of the NDE as a whole, overlapping the other components.

\section{Stage Two: The Out-of-Body Experience}

The second component often reported to us was suddenly finding oneself outside one's physical body and within the immediate vicinity. Respondents typically said they could see and hear clearly while in this state and often related detailed accounts of events that occurred 
while they were apparently unconscious and reportedly out-of-body. While in this state they could neither be seen nor heard by people around them nor could they have any effect on material objects. Few of the persons we interviewed were aware of how they exited or reentered their bodies. They simply and suddenly found themselves "out" and later regained normal consciousness in their physical bodies. Of our sample, 33 people (66 percent) reported having experienced this component. The following excerpts are illustrative:

A man who was bleeding internally due to a ruptured ulcer said:

It was like I was in the corner of the room and looking back down on the room, and it was like looking through a yellow filter like you would use on a camera. The whole room was like a light yellow color. And there I was, laying on the bed and they had intravenous in me and there were two nurses on my right side and one on my left, there were two more nurses and a doctor and they were doing all of this stuff and the doctor was yelling at them that, you know, what were they trying to do, kill me, because they hadn't done anything before he got there and I just stayed up there in the corner looking down on this and then all of a sudden I was back.

A woman who had a series of out-of-body experiences after being crushed when a large log rolled over her said:

Respondent: I was lying on the sand and I saw my body. I was laying face down ... and I was bleeding out of my mouth and nose and it was just like watching someone else. And I didn't realize it was my body and when I did realize it I blacked out again.

Interviewer: So you did have a clear view?

Respondent: Yeah, I could see it and I could hear it, I could smell the salt, like total faculties, and when I suddenly said, "Oh, that's my body," I then stopped being exterior and didn't recall anything until I got to the hospital.

This woman was unique in saying that her sense of smell was operating.

Another interesting feature of the out-of-body experience was how people related to their bodies when seeing them from an external position. Rather than thinking of their bodies as "them," they expressed a definite feeling of being something other than their bodies.

A woman whose experience occurred during premature childbirth related:

I was having these different kinds of awareness, thinking as I looked down on my body, "You know that wasn't a bad body, but it wasn't me, that 
isn't me down there." That I am friends with myself down there, but I'm still me. And I was aware of still having substance.

A man whose experience occurred during open-heart surgery said:

They were just repairing this earth suit and the real me was just waiting there, waiting for them to get done.

Respondents offered two types of explanations if they believed they were not in their bodies. Many felt that they existed as mind alone while in this state. Others felt that they had substance, a body that corresponded with their physical bodies in almost every detail. One interesting feature of this second body was that it lacked the physical defects their physical bodies had. One woman had been pronounced dead on arrival after an accident and put on a bed of ice. She discovered that although she was deaf in one hear, her hearing was perfect while out of her body.

Apparently, movement while in this state was also unique, as in the following account of the woman who was crushed by a large log:

Respondent: . . like I could move at will or at least I could see at will and be in different places at the same time.

Interviewer: What was movement like?

Respondent: It was like direct teleportation.

Another interesting feature reported of this state was that respondents could see and hear very clearly what was happening around them but could not be perceived by others. They were also unable to have any direct effect on material objects. One young woman related the frustration this caused while out of her body after taking an overdose of sleeping pills and tranquilizers:

Respondent: I couldn't turn off the alarm. I walked over and tried to turn it off, but I couldn't. I couldn't move things.

Interviewer: What were your feelings or sensations during this episode?

Respondent: I was an observer. I felt exactly like I had a body, but I couldn't do anything and that was really frustrating to me.

She reported an interesting change in her mental state:

Interviewer: How did you feel when you did wake up again in your physical body? 
Respondent: I was really groggy. And it was weird because I hadn't been groggy. My mind had been completely clear ... when I had been out of my body, and as soon as I woke up I was really groggy.

One woman in our study had an extended and detailed out-of-body experience after accidentally electrocuting herself while home alone:

The very first thing that I did was to stand up and see the telephone, and it is physically impossible to see the telephone from where I was, so I was seeing through two hallway doors. And chen I went over to call for help and it was just a kind of swish, just kind of over here, not real fast, but I was over here, and I went to pick up the telephone and my hand went through the receiver.

A little later in the interview she had this to say about her cognitive processes in this altered state:

[Thinking is] kind of like thinking but I didn't think in words. It was like a whole section of thought put in the perspective of an understanding.

And she went on to say:

Just for a second, and there was no time so I'm conveying it to you in a feeling now, I wondered where [my dog] was and I immediately ended up outside. On my way back I saw a man walking down the street and it was a knowing, too, and I went to go get his attention and he couldn't see me and when $I$ touched his shoulder my hand just went through him.

Later she spoke about fear in relation to being in this state:

As soon as I was afraid or any time I became afraid, there was a control that I wasn't aware of. I came back to the me in the room. There was a pull, a pulling sensation.

As with leaving the body, few people recalled reentering the body after such an experience. Most simply found that they had somehow reunited with the bodies when they woke up at a later time. One woman, however, was very clear about her reentry. She had been in a very serious automobile accident after which she found herself outside of her body. After viewing many of the events that happened, she said:

Respondent: I remember more or less just slipping in, you know, just joining with the body.

Interviewer: Did you come in through the head, the toes or where? 
Respondent: I came in through the head, just slip right in and I came to and it was 9:30 a.m.

Some respondents reported enhanced perceptual abilities during their out-of-body experiences. A woman who almost died because of an allergic reaction at the age of seventeen said:

I remember laying there and I quit breathing and then all of a sudden I started to become conscious again .... and everything began to draw up and the next thing I knew I separated from my body, BOOM! And I was like three feet away from my body and I was watching everyone and I was also aware of what everyone was thinking and feeling and how the fireman that was working on me had a daughter who wasn't much older than I was and he couldn't stand to see me die.

The woman who was crushed by a large log said of her experience:

[While I was out of my body] I didn't have any problems. For some reason I could look at things, if anything came up... Once I saw two nurses arguing and I could see why they were arguing. I could perceive things that maybe, you know, couldn't be perceived by people running through bodies.

This woman was in a coma for twelve days and in and out of her body a number of times during those twelve days. During one out-of-body experience she recalled perceiving other people who were also out of their bodies:

Respondent: Yeah, I remember at least three of them who were kind of going through the same trip. They had gotten in a real bad accident and we didn't really communicate. It was a kind of a recognition in a way ... and two of them had pictures of still being stuck in this accident ...

Interviewer: What do you mean, pictures?

Respondent: it was like real intense vibrations.

One woman in our study felt that she had a white garment on while out-of-body:

Interviewer: So you had another body?

Respondent: I was aware in a sense that I had white on, that I had something white on .... a garment, and I could see through it and it was kind of white and it was kind of misty and it was like cheese cloth.

This same woman was the only one in our study who perceived a 
connection between her physical body and her second body:

I turned around and saw a piece of silver tinsel on the ground and I never knew what it was... but I had a sense of it being hooked to me and it being hooked to my physical body.

For many of the people interviewed, their NDE consisted of the first two components. After experiencing themselves outside of their physical bodies, along with the wondrous feelings of peace and calm, they reported simply regaining normal consciousness in their physical bodies. For others, the experience continued.

Stage Three: The Tunnel or Dark Area

After finding themselves outside of their bodies, some respondents said they next found themselves in a dark dimensionless space or void. The analogy of a tunnel was the one most often used, although many people simply said they were in an extremely dark place. Most said they were definitely moving through tunnels; 16 respondents (32 percent) reported this component.

A man who was electrocuted as a teenager said:

I was just drifting, and I was in this dark, dark place. There was a light at the end and I felt very calm, very peaceful... It was like a hose. You just take a hose and you're turning the water on in the hose and then all of a sudden spraying out. That's exactly what I felt.

A man who drowned while scuba diving said:

It was like swirling blackness, like, um, it'd be like what I imagine a deep sea diver would see when he was down so far that no light could penetrate.

Movement while in this state was most often described as floating or spinning, as in this account from a woman whose experience occurred while undergoing emergency surgery:

I was floating through, I'd say a tunnel ... It was like a tunnel or a cylinder, because you know there is space or some type of boundary there even though you can't feel it and you are going in a specific direction.

A woman whose experience occurred during a difficult childbirth said:

I was like floating and I could see myself and it was dark and yet there was a brightness about it and I was floating like this [indicates sideways] 
... but all this darkness was tunneled towards this light.

\section{Stage Four: The Light}

The fourth component reported by Ring (1980) and others was a brilliant light. In our study, 31 persons ( 62 percent) reported such an occurrence. Persons who had the tunnel experience often would report that the light was at the end of the tunnel or extended into the tunnel. People also reported feeling drawn to the light or knowing that the light was their destination. Others who did not report a tunnel experience simply found themselves in an area that was highly illuminated. Respondents said the light appeared not to have a source and that it did not hurt their eyes.

A man who was electrocuted said:

I kept looking at the end of this so-called tunnel and I saw a light and I just kept getting closer and closer . . . and then when I got to the light all of a sudden my eyes focused ... Instantaneously as $I$ hit the end of that hole I gasped and came to.

A woman who was shot said that while she was traveling down a tunnel:

Respondent: I was going in a specific direction and I saw a light. What was carrying me there I don't know. It was more or less like a gravitational pull.

Interviewer: Where was the light in relation to the tunnel?

Respondent: Like at the end. First of all while I was in there I didn't see no light, but as I kept traveling I finally did see the light. And this is how I felt. That after I reached the light it would more or less be heaven.

Stage Five: Entering the Light

The last and deepest core component identified by Ring (1980) was what he called entering the light. We found that many of our respondents had difficulty deciding whether they actually entered the light. Many stated they came right up to the light but did not actually enter it. Others said the light seemed to be all around them but were unsure whether that constituted being in it. Still others reported they found themselves in beautiful pastoral settings but did not report going into a light on their way there. Lindley, Bryan, and Conley (1981) suggested the term Inner Setting to describe this last component. 
There seemed to be two kinds of experiences reported for this component. Some of our respondents reported entering a light and becoming one with the light. In so doing they were in a state of allknowing in which they intuitively knew or were made aware of the meaning of life as well as many other things. Others found themselves in beautiful pastoral settings. In these settings they were aware of having bodies and of having a total sensory experience. In our sample, 9 persons (18 percent) reported having one of these two experiences.

A woman who had an allergic reaction at age seventeen stated:

I found myself incredibly drawn to the light and it was like being a phoenix is the only way I can describe it. Like going towards the sun, you know that mythical character who went to the sun and wanted to be consumed by it. So I rushed towards this light and I became one with the light and in becoming one with the light I also received the knowledge of the light.

Another woman, whose experience occurred during childbirth, believed she was returning to a place she had been before:

Respondent: I suddenly was in the midst of this light and I thought, "Of course, I should have known!" It was like returning home after being away for a long time.

Interviewer: So it was like somewhere you had been before?

Respondent: Everything came back to me just like that.

Interviewer: What do you mean everything?

Respondent: As far as why we had to go there, which is really here of course, and the fact that we do go back to this, and that you have to learn things, you have to do whatever and then you get to come back again. It was just like returning home after being away, like returning to somewhere I had been before and I thought, "How stupid of me not to remember." It would have been very valuable to have known this back there ... to realize that I was where I was supposed to be and that this was the real thing not that. I mean not being a body and being on earth.

Later in the interview she said:

I didn't see a ball of light coming at me. I was in the midst of the light. It was everywhere, above me, below me and through me. I was part of the light and you just have a feeling of such total love that you cannot believe, and peace. 
The following description was given by a woman with a degenerative neuromuscular disease who reported having been clinically dead on three separate occasions and having the same experience each time:

And then I was no longer there, I was somewhere else again. And this is the part that sounds, a lot of people go, well, so I don't tell it too often. I was out in the country, and I've had dreams before in color, but this was the only dream that I ever had that was a total experience for all of my senses. Odors, OK, country odors, birds singing, the sound of air moving through the grasses. I was physically perfect, how I was when I was fourteen years old, OK, not too fat, not too thin, just fine ... And I was walking down this country road and it was a dirt road. I could feel the warmth of the dust on top and the coolness beneath, the moist coolness, because it puffed up under my toes. My vision was perfect. I wasn't wearing glasses at all and I've been wearing glasses since I was five years old. And I came to this tree that had fallen across this narrow road. It was a tremendous tree. It stood about as high as the top of this room and it had fallen across this road and it was dead. I could see the roots sticking up and there were other essences around me.

\section{Related Phenomena}

Many respondents reported viewing the spirits of dead relatives or friends, or of religious figures or beings. Others heard voices of deceased persons or spiritual beings. Of our respondents 24 (48 percent) reported such an occurrence.

A woman whose experience occurred during open-heart surgery said she heard the voice of her late spiritual leader as she went down the tunnel:

I heard him, I didn't see him, but I heard him say, "Not yet, [her nickname]" and there was a chuckle in his voice.

Others said they were accompanied by a presence or by the spirits of dead relatives and friends. A man who suffered a cardiac arrest said:

... and then, that was it. I had a cardiac arrest ... What you did then, you were accompanied by a presence ... You look at it and you think that it was a figure, but it wasn't. You go through thoughts that it is like a neon sign in the shape of a figure, but it wasn't. What you come down to is it is a light, but it's more of an idea, more of an idea that accompanies you, and you were very comfortable ... It was like a person is trying to show you something yet no words are exchanged. That's why I say it was like being with an idea. 
A man who suffered a spinal-cord injury at the age of seventeen after diving into a shallow river had a conversation and was given a reason to return:

The lights went out and I was in this blackness, but this bright, brilliant light I saw, and a hand reached down and I stretched out my hand and grabbed onto it. And it pulled me out of this blackness into the light and I had no sensation of fear or pain, really euphoric and ecstatic. I was pulled or drawn into this place and there I had some conversations with this being and a lot of questions were answered just as I thought up the question, you know. And I thought, WOW, this is really neat. I remember having the thought, What is the cure for cancer, such a big thing and you know, BAM, I had the answer right away. And it was so simple, it is so damn simple why didn't anybody think of it. This being said, "You've got to go back, it's not your time yet." There was something that I was supposed to do and I remember him saying, "Tell about your experience." We conversed for a while longer and then all of a sudden I was sliding down and he held my hand and then he let me go and I went back into the blackness and then I woke up.

Many of those interviewed expressed a familiarity with the presence or being they encountered. The following is from a woman who found herself outside of her body after having an allergic reaction. After watching resuscitation attempts for a while, she said:

I didn't know where to go and then I thought, "Gee I'm really alone." And then I recognized my uncle who had died a couple of years before and I was really thrilled to see him, although he wasn't in physical form. I recognized him by his pattern, I guess you might say.

This same woman reported having been visited by her grandfather while very sick and not being expected to live at the age of six:

And then all of a sudden a man appeared to me, a really nice man and he sat next to me on my bed and he comforted me and I told him that I was afraid of dying and I didn't really know how to handle this and that my mother was very sad. So this man, who I really didn't know, sort of took me from this world.

Only six years later when this woman saw a picture of her maternal grandfather, she said, did she realize that it was he who had visited her.

A woman whose experience occurred following an injection in her doctor's office said:

And then I saw this chair. It was like the chair that Abraham Lincoln sits in at the Lincoln Memorial. And it was huge and there was someone 
sitting in the chair. It was so bright and the chair was white and the person sitting in the chair was white and over to the side of the chair there was a jury box and there were people sitting in it and they were white. The only thing that was said to me was-he called me by name and said-"Are you ready?" And I said, "No, give me more time." Then I opened my eyes and I was on the table gasping.

A woman who attempted suicide said:

I was in a swamp . . . and I just kept going and going and finally I got past this swamp and there was this beautiful white gate. It was so beautiful, with beautiful flowers and the flowers were so tall . . . and my grandmother had died about two years before that and she stood at the gate, at the opening, and she was beckoning me to come. When I saw my grandmother $I$ was maybe twenty feet away from her and I fell on the ground and I said, "Grandmother come and get me." She called to me and said that she couldn't come get me, that I had to make it on my own ... and it seemed like forever, but it was just a short time ... and finally she told me to go back, that "It isn't time for you," and she kept telling me to go back. And I was begging her to help me because I didn't want to go back, I wanted to go into this beautiful kingdom that I had seen. It was so gorgeous. It was white, the whole place was white and it was like wrought iron and it looked like a beautiful kingdom. Then I woke up at the hospital and they had put me in the corridor and they were just waiting for me to die.

A woman with a neuromuscular disorder said:

Respondent: There were other essences around me.

Interviewer: Where?

Respondent: O.K., where in this experience I had another body with which I was perceiving things, I experienced these other essences, other people whom I didn't recognize except to say that I recognized their essences. I just recognized them as being familiar to me ... and they were just waiting there with a kind of joyous expectation and I was also aware that they totally understood me.

Later in the same interview she described another presence:

And then I felt this much larger presence, more toward the physical, even though he wasn't physical, he was still just an entity. He was beside me on my right side and very quietly with a note of regret he said, "You have to go back." And I got hysterical and I could feel the tears in my eyes and I tried to climb over this tree and I couldn't. And he said again, "No, you have to go back." That ended the experience and when I woke up, I was in the intensive care unit and it was the first time in three days that I had been awake.

Finally, a woman who is a very devout Christian said: 
I left the operating room altogether and I was in another place immediately with Christ. I mean, I was just there, and, uh, it is still emotional for me. I mean it was just such an overwhelming feeling of being back home. Not being home, but being back home. That I had left home temporarily, and I remember saying, and I could hear the words. I remember saying, "I am so glad to be back home." and it was like a reunion and it was perfect love and perfect acceptance, uh, and I said something about, time was involved. I said, "It seems like it's been a long time," I remember a lot of time was spent on just, you know, I'm giad to be back home. I remember him saying, "I missed you." Then I must have sensed that it wasn't going to be a permanent homecoming because then I began to say, "I'm going to be staying aren't I?" And then He said, "No, [her name], He used my name and He said, "I've allowed you to have this experience and it will never leave you. It will always be vivid in your mind, because there is much work for you to do yet. You must go back, but this will always energize and strengthen you because you know that you are you wherever you are and that I am always with you."

Other researchers have found that many people who come close to death report having seen vivid images of their life flash in front of them in very rapid sequence. Six respondents (12 percent of our sample) reported such an occurrence. A woman whose experience occurred during a difficult pregnancy said:

I just could see myself as a little girl, and it's hard to explain. I could see myself standing in a crib and I remembered a nightmare that $I$ had had as a child, and I saw scenes from dancing lessons that I took as a child. It was like flashes, like specific events, but I can't remember them all.

Also, a woman who electrocuted herself accidentally said:

It was like watching a movie and being in the movie at the same time. The guide or presence was next to me and I had the feeling that she was monitoring what I was seeing. It was just selected scenes from my childhood.

One final issue to touch on is what the experiencers said about the reality of the experience. Although there doesn't seem to be any way to answer the question, "Was this a real experience?" in any objective way (although Sabom (1982) offered some very interesting evidence), to the experiencers themselves it was very real. Only 2 people of our sample equivocated on this issue. The rest, 96 percent, said it was a real experience. One man had this to say:

Interviewer: Was this experience like a dream or was it different than a dream?

Respondent: It was like reality. It was like I was standing there in that 
room and it was happening and I was aware of what was going on. They were running tubes down my throat and I thought, "Man that must really hurt."

And a woman said:

Interviewer: Was this like a dream or was it different than a dream?

Respondent: Different.

Interviewer: How so?

Respondent: It was like real life ... It didn't have any of that type of floating sensation that I get when I dream.

Finally, a male respondent said:

Interviewer: Was this like a dream or was it different than a dream? Respondent: It wasn't like a dream, in fact, it was more real than life!

\section{DISCUSSION}

We do not feel our results represent a population of persons who come close to death but, rather, are biased in favor of persons who had some type of experience. Because of this we decided to present our findings in descriptive and qualitative terms rather than quantitative. However, our main objective, to locate and interview a sample of persons who reported NDEs, was achieved. In comparing our results with those of Ring (1980) (see Table), our percentages are somewhat higher, as would be expected based on the different sampling procedures. It is interesting to compare our results with those of Lindley, Bryan, and Conley, whose methodology and number of respondents were close to our own.

Although our results support Ring's (1980) contention that the NDE unfolds in a sequentially stable manner, there are some differences between our findings and his worth mentioning. Although most of our respondents reported the affective component first and the out-of-body experience second, some of our respondents reported these components in reverse order. Moody reported first the out-of-body and then the affective component.

We did not find proportionally as many tunnel experiences as Ring did. The tunnel experiences we did uncover were almost always in connection with seeing the light and, less frequently, with entering the light. In fact, many of our respondents appeared to provide the analogy of a tunnel only after seeing the light at the end. On the 


\section{PERCENTAGES OF NEAR-DEATH EXPERIENCERS \\ REPORTING SEQUENTIAL NDE STAGES}

Stage

Study

$\begin{array}{ll}\text { Ring (1980) } & \text { Lindley, Bryan } \\ \text { Conley (1981) }\end{array}$

Present

study

1. Core Affective

Cluster

$60 \%$

$74.5 \%$

$70 \%$

2. Out-of-Body

Experience

$37 \%$

$70.9 \%$

$66 \%$

3. Tunnel/Dark

Area

$23 \%$

$38.2 \%$

$32 \%$

4. Seeing the Light

$16 \%$

$56.4 \%$

$62 \%$

5. Entering the

Light

$10 \%$

$34.5 \%$

$18 \%$

other hand, many of our respondents reported experiencing a light without going through a tunnel or dark area.

Ring (1980) reported that some of his respondents entered the light and found themselves in beautiful pastoral settings. Although we found persons who entered a light and persons who found themselves in beautiful pastoral settings, we did not find a single example of a person entering a light and then finding himself in a beautiful pastoral setting. Some respondents suddenly found themselves in beautiful settings but did not report the early components. Others did report the earlier components and also reported entering a light and becoming one with it. It is our impression that these are variations of a similar experience.

Lindley, Bryan, and Conley (1981) reported that the positive aftereffects of the experience were the most frequently mentioned result of the experience for respondents. Our subjects also felt definite shifts in values away from materialistic and towards spiritual goals. Experiencers appeared to be more loving, more aware of their relationships with others, and more conscious of the meaning and purpose of their lives. And subjects reported less fear of death or no fear at all. Their NDE seemed to have given them an unshakable conviction that they will exist following physical death. This is particularly interesting in light of the fact that one of our sample professed to be an atheist and four more said they had no religion. 
Our results and those of many researchers before us (Moody, 1975; Ring, 1980; Ring and Franklin, 1981; Lindley, Bryan, and Conley, 1981; Lundahl, 1979; Sabom, 1982) leave little doubt that the NDE is a unique psychological phenomenon that merits further study. No longer able to dismiss it but as yet unable to explain it within the context of existing scientific knowledge, we must turn elsewhere for an interpretation of this phenomenon. What is an NDE, and what are its implications for the study of consciousness and transpersonal psychology?

What strikes us more in attempting to explain this phenomenon is that it is so extraordinary that it is difficult to place it anywhere on the same continuum with normal consciousness and consensual reality and feel comfortable with it. Indeed, our very beliefs about what is real, and therefore possible, are often stretched by these accounts. And yet, based on the overwhelming number of respondents questioned, these experiences carry with them an undeniable feeling of reality.

A truly adequate and comprehensive interpretation of the NDE is certainly years, maybe decades away. Although it may seem to many that the NDE contradicts and undermines much of what science has been able to uncover, we feel that it extends rather than refutes what we already know much in the same way that Einstein's view of the universe extended Newton's. However, the implications the NDE presents us are potentially so revolutionary that at this point in history, when mankind has harnessed enough energy to destroy itself many times over, a deeper understanding of ourselves and our continuum might be crucial.

\section{ACKNOWLEDGEMENT}

We wish to express our appreciation to Patricia Adams for her assistance in the editing of this paper.

\section{REFERENCES}

Grof, S., and Halifax, J. The Human Encounter With Death. New York: Dutton, 1977.

Heim, A. Notizen Uber den Tod durch Absturz. Jahrbuch des Schweizer Alpenklub, 1892, 27, 327-337. 
Lindley, J., Bryan, S., and Conley, B. Near-death experiences in a Pacific Northwest population: The Evergreen study. Anabiosis, 1981, 1, 104-124.

Lundahl, C. The near-death experience among Mormons. Paper presented at the American Psychological Association Annual Convention, New York, 1979.

Moody, R.A. Life After Life. Atlanta: Mockingbird Books, 1975. Ring, K. Life at Death. New York: Coward, McCann, and Geoghegan, 1980.

Ring, K., and Franklin, S. Do suicide survivors report near-death experiences? Omega, 1981, 12, 191-208.

Ring, K. Paranormal and other non-ordinary aspects of near-death experiences: implications for a new paradigm. Essence, 1981, 5, 33-51.

Sabom, M. Recollections of Death. New York: Harper and Row, 1982.

Requests for reprints to:

J. Timothy Green

Box 4548

Agana, Guam 96910

Penelope Friedman

9628 Reseda Blvd., \#101

Northridge, California 91324 
